\title{
CHRONIC OBSTRUCTIVE PULMONARY DISEASE
}

\section{Inhaled short acting $\beta$ agonist use in COPD and the risk of acute myocardial infarction}

\author{
S Suissa, T Assimes, P Ernst
}

Thorax 2003;58:43-46

See end of article for authors' affiliations

.....................

Correspondence to: Dr S Suissa, Division of Clinical Epidemiology, Royal Victoria Hospital 687 Pine Avenue West Ross 4.29, Montreal, Québec H3A 1A1,

Canada;

samy.suissa@

clinepi.mcgill.ca

Revised version received 21 August 2002

Accepted for publication 21 September 2002

\begin{abstract}
Background: A recent study found that short acting $\beta$ agonists used in the treatment of asthma and chronic obstructive pulmonary disease (COPD) may increase the risk of acute myocardial infarction. We investigated this hypothesis in patients with COPD already at high risk of cardiac disease.

Methods: The Saskatchewan Health Services databases were used to form a population based cohort of all patients newly diagnosed with COPD over the age of 55 years identified between 1980 and 1997. All subjects were followed up until 1999, death, or the first occurrence of acute myocardial infarction. Those with a first acute myocardial infarction, fatal or non-fatal, were matched on calendar time and age with cohort members.

Results: The cohort consisted of 12090 subjects including 1127 cases with fatal or non-fatal acute myocardial infarction. The adjusted rate ratio for current use of inhaled $\beta$ agonists was 1.12 (95\% confidence interval (Cl) 0.95 to 1.33), and for first time use it was 1.02 (95\% $\mathrm{Cl} 0.52$ to 2.00$)$. There was also no significant increase in risk when the analysis was restricted to subjects with cardiac risk factors such as hypertension and diabetes, or to subjects not having been prescribed $\beta$ blocker medications. Conclusion: Short acting inhaled $\beta$ agonist use among patients with COPD does not appear to increase the risk of fatal or non-fatal acute myocardial infarction.
\end{abstract}

$\mathrm{B}$ ronchodilators, particularly $\beta$ agonists, used in the treatment of asthma and chronic obstructive pulmonary disease (COPD), are known to have several side effects with potential effects on cardiac function. ${ }^{12}$ These effects, usually considered to be mild, include an increase in heart rate, an increase in contractile force, a decrease in peripheral vascular resistance with increased pulse pressure, an increase in cardiac output, as well as changes in serum potassium and magnesium levels which may affect conduction pathways in the heart. ${ }^{4}$

While oral and nebulised forms of $\beta$ agonists have been found to increase the risk of acute cardiac death in a cohort of asthma patients, primarily in patients with concomitant cardiac disease, inhaled $\beta$ agonists delivered by metered dose inhalers were not associated with an increase in risk of cardiac death. $^{5}$ A recent case-control study suggested that new one-time use of inhaled $\beta$ agonists in people with existing cardiovascular disease increases the risk of myocardial infarction (MI), while more frequent users of inhaled $\beta$ agonists and those without cardiovascular disease were not found to be at risk. ${ }^{6}$ This study, however, has certain limitations that may have biased the findings. For instance, oral and nebulised forms of $\beta$ agonists, that are likely to be prescribed more frequently to subjects also receiving the commonly prescribed metered dose inhaler formulation of these medications, were not identified or accounted for in the analysis as potential confounders or as higher dose formulations of $\beta$ agonists. Moreover, the study examined use of $\beta$ agonists in the entire population and thus included a majority of patients who did not have asthma or COPD, the usual indication for inhaled $\beta$ agonists. As COPD is a risk factor for $\mathrm{MI}^{7}$ restricting the analysis to subjects with asthma or COPD may have been indicated.

To address these limitations we conducted a populationbased epidemiological study to assess whether short acting inhaled $\beta$ agonists increase the risk of acute $\mathrm{MI}$ in a large cohort of patients with COPD

\section{METHODS}

\section{Subjects and source of dato}

The cohort of patients with COPD was identified using the computerised databases of Saskatchewan Health. These databases were developed to aid in the administration of a universal publicly funded health insurance programme. Over $99 \%$ of Saskatchewan residents (approximately 1 million) are covered by this programme and, of these, about $91 \%$ are also eligible for outpatient prescription drug benefits. Insured medical, hospital, and outpatient prescription drug services and vital status are recorded for all beneficiaries and may be linked for each individual using a unique health services number. The databases have been used extensively to study the effects of several prescription drugs at the population level. ${ }^{8}$

The cohort was formed from all subjects newly treated for a likely diagnosis of COPD. Subjects were included if they had been dispensed at least three prescriptions for a bronchodilator ( $\beta_{2}$ agonist, inhaled anticholinergic, or theophylline) within a 1 year period between 1 January 1980 and 31 December 1997. These three prescriptions had to be dispensed on at least two different dates within the year. The date of the third prescription was taken as the date of cohort entry. Only subjects who were at least 55 years old at cohort entry were included. To confirm the incident nature of the treatment and to exclude asthma patients, subjects were excluded if they had been prescribed any bronchodilators or other asthma drugs including inhaled corticosteroids, nasal corticosteroids, cromones (cromoglycate and nedocromil), and ketotifen during the 5 year period before cohort entry. All subjects were followed until the date of death, the date of emigration from the province, the date of end of coverage of the health insurance plan, or 31 December 1999, whichever occurred first.

\section{Outcome}

All cases of acute myocardial infarction that occurred during the cohort follow up were ascertained in two ways: a primary discharge diagnosis of MI (ICD-9 code 410) on the hospital services file or an underlying cause of death of MI (ICD-9 code 410) on the vital statistics file. For subjects with multiple 
Table 1 Characteristics of cases and controls

\begin{tabular}{|c|c|c|}
\hline & $\begin{array}{l}\text { Cases } \\
(n=1127)\end{array}$ & $\begin{array}{l}\text { Controls } \\
(n=10766)\end{array}$ \\
\hline Mean (SD) age at index date* & $77(8.3)$ & $77(8.0)$ \\
\hline Sex (\% male) & 69 & 55 \\
\hline \multicolumn{3}{|c|}{$\begin{array}{l}\text { Use of drugs for cardiovascular disease or risk factors during the yea } \\
\text { before index date }(\%) \text { : }\end{array}$} \\
\hline Any & 80 & 63 \\
\hline Hypertension & 75 & 57 \\
\hline Beta-blockers & 11 & 6.6 \\
\hline Other & 74 & 55 \\
\hline Angina & 34 & 13 \\
\hline Congestive heart failure (CHD) & 31 & 16 \\
\hline Other CHD drugs $†$ & 7.8 & 4.4 \\
\hline Diabetes & 16 & 7.8 \\
\hline \multicolumn{3}{|c|}{ Use of COPD medications during the year before index date (\%): } \\
\hline Inhaled $\beta_{2}$ agonists & 43 & 42 \\
\hline Oral $\beta_{2}$ agonists & 11 & 10 \\
\hline Nebulised $\beta_{2}$ agonists & 13 & 9 \\
\hline Xanthines & 32 & 29 \\
\hline Ipratropium bromide & & \\
\hline Oral corticosteroids & 19 & 14 \\
\hline Nasal corticosteroids & 3.4 & 4.6 \\
\hline Inhaled corticosteroids & 25 & 27 \\
\hline \multicolumn{3}{|c|}{$\begin{array}{l}\text { *Age was a matching factor. } \\
\text { †Includes amiodarone, disopyramide, flecainide, mexiletine, } \\
\text { procanamide, propafenone, quinidine, tocainide, and lipid lowering } \\
\text { agents. }\end{array}$} \\
\hline
\end{tabular}

events, the first occurrence of acute myocardial infarction was taken as the case event. Cases occurring during or within a year of the period July 1987-December 1988 (18 months) were excluded because capture of outpatient prescription drug data was incomplete during this 18 month period.

\section{Study design}

A nested case-control design was used to permit analysis of the complex time varying nature of the exposure. ${ }^{9}$ Each case was matched to all controls available within the cohort on the basis of three factors: (1) all matched controls for a case had a duration of follow up at least as long as the time to acute MI for the corresponding case (this was achieved by assuring that each control was in the cohort and therefore at risk for the outcome at the date of the acute MI in the case, a date designated as the index date); (2) to control for secular trends in inhaled $\beta$ agonist use, the matched controls had the same cal- endar year of cohort entry as the case; (3) the controls were matched to the cases for age within a year of the date of birth.

\section{Exposure to $\beta$ agonists}

All prescriptions of inhaled, oral, or nebulised $\beta$ agonists that were dispensed to the cases and controls during the year before their index date were identified, as well as at any time between cohort entry and the index date. Each prescription was analysed to identify the number of canisters of inhaled $\beta$ agonist dispensed concurrently.

\section{Data analysis}

The presence of any use of $\beta$ agonists during the 1 year period before the index date was determined and the number of canisters dispensed during this period was computed. Current exposure to inhaled $\beta$ agonists was considered as any prescription dispensed in the 2 month period before the index date. To assess the effect of new use of inhaled $\beta$ agonists we considered currently exposed subjects who had not received $\beta$ agonists of any form during the 3-12 months before the index date. In addition, first time use of inhaled $\beta$ agonists was defined as current use preceded by no $\beta$ agonists since cohort entry.

Conditional logistic regression for matched case-control data was used to estimate adjusted rate ratios of acute MI associated with the use of inhaled $\beta$ agonists. To assess the quantity-response effect we first stratified use into: no use, $\leqslant 1.5$ canisters per month, and $>1.5$ canisters per month. We also examined the quantity response on a continuous basis per canister dispensed in the year before the index date and estimated the risk per 10 canisters of inhaled $\beta$ agonists dispensed in the previous year. To control for any residual confounding beyond age we adjusted all rate ratio estimates for the number of prescriptions of other asthma drugs, including theophylline and all corticosteroids, dispensed in the year before the index date. We also adjusted for the presence of cardiovascular risk factors as measured by prescriptions of drugs for the treatment of hypertension, congestive heart failure, angina, arrhythmia, hyperlipidaemia, and diabetes dispensed during the year before the index date, as well as sex.

\section{RESULTS}

The cohort included 12090 subjects (60\% male) with a mean age at entry to the cohort of 73 years. A total of 1310 subjects with fatal and non-fatal acute MI were identified during follow up. We eliminated 190 of these because they occurred

Table 2 Adjusted rate ratio of fatal and non-fatal acute myocardial infarction for inhaled $\beta_{2}$ agonist use during the year before the index date

\begin{tabular}{|c|c|c|c|c|c|}
\hline & \multirow[b]{2}{*}{$\begin{array}{l}\text { Cases } \\
(n=1127)\end{array}$} & \multirow[b]{2}{*}{$\begin{array}{l}\text { Controls } \\
(n=10766)\end{array}$} & \multirow[b]{2}{*}{$\begin{array}{l}\text { Crude rate } \\
\text { ratio }\end{array}$} & \multicolumn{2}{|c|}{ Adjusted* } \\
\hline & & & & $\begin{array}{l}\text { Rate } \\
\text { ratio }\end{array}$ & $95 \% \mathrm{Cl}$ \\
\hline \multicolumn{6}{|c|}{ One year before index date } \\
\hline No use $(\%)$ & 57.4 & 58.0 & 1.00 & 1.00 & Reference \\
\hline Any use $(\%)$ & 42.6 & 42.0 & 1.06 & 1.06 & 0.92 to 1.23 \\
\hline $1-17$ MDls (\%) & 38.1 & 38.3 & 1.03 & 1.05 & 0.90 to 1.21 \\
\hline$\geqslant 18 \mathrm{MDls}(\%)$ & 4.5 & 3.7 & 1.28 & 1.31 & 0.94 to 1.83 \\
\hline Mean (SD) no MDIs $†$ & $3.2(6.9)$ & $2.9(6.1)$ & 1.08 & 1.11 & 0.99 to 1.23 \\
\hline \multicolumn{6}{|l|}{ Current use $\ddagger$} \\
\hline Any current use $(\%)$ & 24.2 & 23.2 & 1.08 & 1.12 & 0.95 to 1.33 \\
\hline New use $(\%) \S$ & 2.0 & 1.8 & 1.08 & 1.12 & 0.69 to 1.80 \\
\hline First time use $(\%)$ & 1.0 & 1.0 & 0.92 & 1.02 & 0.52 to 2.00 \\
\hline
\end{tabular}

*Adjusted (after age matching) for sex, number of prescriptions for oral corticosteroids, nasal corticosteroids, inhaled corticosteroids, oral $\beta_{2}$ agonist, nebulised $\beta_{2}$ agonist, and xanthines in the year before the index date, and presence of cardiovascular risk factors (angina, hypertension, congestive heart failure, arrhythmia, hyperlipidemia and diabetes) in the year before the index date.

†Rate ratio per additional 10 metered dose inhalers (MDIs) of inhaled $\beta_{2}$ agonist.

$\ddagger$ Use of inhaled $\beta_{2}$ agonist in the 2 months before the index date.

$\S$ Current use of inhaled $\beta_{2}$ agonist with no other $\beta_{2}$ agonist use of any form during the year before the index date. 
Table 3 Adjusted rate ratio of fatal and non-fatal acute myocardial infarction (MI) for inhaled $\beta_{2}$ agonist use during the year before the index date according to concurrent cardiovascular disease and $\beta$ blocker use

\begin{tabular}{|c|c|c|c|c|c|}
\hline & \multirow[b]{2}{*}{$\begin{array}{l}\text { Cases } \\
(n=1127)\end{array}$} & \multirow[b]{2}{*}{$\begin{array}{l}\text { Controls } \\
(n=10766)\end{array}$} & \multirow[b]{2}{*}{$\begin{array}{l}\text { Crude } \\
\text { rate ratio }\end{array}$} & \multicolumn{2}{|c|}{ Adjusted* } \\
\hline & & & & $\begin{array}{l}\text { Rate } \\
\text { ratio }\end{array}$ & $95 \% \mathrm{Cl}$ \\
\hline \multicolumn{6}{|c|}{ Subjects with no previous cardiac risk factors: } \\
\hline$n$ & 220 & 3982 & & & \\
\hline No use in past year & 59.1 & 57.0 & 1.00 & 1.00 & Reference \\
\hline Current use & 24.6 & 25.0 & 1.00 & 0.97 & 0.70 to 1.36 \\
\hline New use & 2.7 & 1.9 & 1.58 & 1.61 & 0.68 to 3.79 \\
\hline First time use (\%) & 0.9 & 1.0 & 0.93 & 1.00 & 0.24 to 4.24 \\
\hline \multicolumn{6}{|c|}{ Subjects with previous cardiac risk factors: } \\
\hline $\mathrm{n}$ & 907 & 6784 & & & \\
\hline No use in past year & 57.0 & 58.6 & 1.00 & 1.00 & Reference \\
\hline Current use & 24.2 & 22.2 & 1.12 & 1.17 & 0.97 to 1.41 \\
\hline New use & 1.8 & 1.8 & 0.97 & 0.99 & 0.56 to 1.73 \\
\hline First time use (\%) & 1.0 & 1.0 & 0.94 & 1.03 & 0.48 to 2.19 \\
\hline \multicolumn{6}{|l|}{ Non-users of $\beta$ blockers: } \\
\hline$n$ & 1002 & 10051 & & & \\
\hline No use & 55.5 & 57.2 & 1.00 & 1.00 & Reference \\
\hline Current use & 25.3 & 23.7 & 1.14 & 1.20 & 1.00 to 1.44 \\
\hline New use & 2.1 & 1.8 & 1.25 & 1.32 & 0.80 to 2.17 \\
\hline First time use (\%) & 1.0 & 1.0 & 1.03 & 1.10 & 0.52 to 2.34 \\
\hline \multicolumn{6}{|c|}{$\begin{array}{l}\text { *Adjusted (after age matching) for sex, number of prescriptions for oral corticosteroids, nasal corticosteroids } \\
\text { inhaled corticosteroids, oral } \beta_{2} \text { agonist, nebulised } \beta_{2} \text {-agonist, and xanthines in the year before the index } \\
\text { date, and presence of cardiovascular risk factors (angina, hypertension, congestive heart failure, arrhythmia } \\
\text { hyperlipidaemia, and diabetes) in the year before the index date. }\end{array}$} \\
\hline
\end{tabular}

Table 4 Adjusted rate ratio of fatal and non-fatal acute myocardial infarction (MI) for nebulised and oral $\beta_{2}$ agonist use during the year before the index date

\begin{tabular}{|c|c|c|c|c|c|}
\hline & \multirow[b]{2}{*}{$\begin{array}{l}\text { Cases } \\
(n=1127)\end{array}$} & \multirow[b]{2}{*}{$\begin{array}{l}\text { Controls } \\
(n=10766)\end{array}$} & \multirow[b]{2}{*}{$\begin{array}{l}\text { Crude } \\
\text { rate ratio }\end{array}$} & \multicolumn{2}{|c|}{ Adjusted* } \\
\hline & & & & $\begin{array}{l}\text { Rate } \\
\text { ratio }\end{array}$ & $95 \% \mathrm{Cl}$ \\
\hline \multicolumn{6}{|c|}{ Nebulised $\beta_{2}$ agonist use ${ }^{*}$ during year before index date: } \\
\hline No use & 87.2 & 90.7 & 1.00 & 1.00 & Reference \\
\hline Any use & 12.8 & 9.3 & 1.44 & 1.12 & 0.90 to 1.38 \\
\hline No of prescriptions $\dagger$ & $0.7(2.5)$ & $0.6(2.4)$ & 1.20 & 0.91 & 0.69 to 1.19 \\
\hline \multicolumn{6}{|c|}{ Oral $\beta_{2}$ agonist use $\ddagger$ during year before index date } \\
\hline No use & 89.1 & 89.7 & 1.00 & 1.00 & Reference \\
\hline Any use & 10.9 & 10.3 & 1.05 & 0.99 & 0.80 to 1.23 \\
\hline No of prescriptions $\dagger$ & $0.5(1.8)$ & $0.5(1.9)$ & 0.92 & 0.79 & 0.55 to 1.12 \\
\hline \multicolumn{6}{|c|}{$\begin{array}{l}\text { *Adjusted for sex, number of prescriptions for oral corticosteroids, nasal corticosteroids, inhaled } \\
\text { corticosteroids, inhaled } \beta_{2} \text { agonist, oral } \beta_{2} \text { agonist and xanthines in the year before the index date, and } \\
\text { presence of cardiovascular risk factors (angina, hypertension, congestive heart failure, arrhythmia, } \\
\text { hyperlipidaemia and diabetes) in the year before the index date. } \\
\text { †Rate ratio per additional } 10 \text { prescriptions. } \\
\ddagger \text { Adjusted for sex, number of prescriptions for oral corticosteroids, nasal corticosteroids, inhaled } \\
\text { corticosteroids, inhaled } \beta_{2} \text { agonist, nebulised } \beta_{2} \text { agonist and xanthines in the year before the index date, anc } \\
\text { presence of cardiovascular risk factors (angina, hypertension, congestive heart failure, arrhythmia, } \\
\text { hyperlipidaemia, and diabetes) in the year before the index date. }\end{array}$} \\
\hline
\end{tabular}

during the period when complete outpatient prescription drug data were not available and seven because no matched controls could be identified. The remaining 1127 cases (406 fatal MI, 721 non-fatal MI) were matched to 10766 controls. The characteristics of these cases and their matched controls are shown in table 1 . As expected, cases were more likely to be male and were receiving more medications for cardiovascular disease than controls.

Table 2 shows the crude and adjusted rate ratios of acute MI associated with the use of inhaled $\beta$ agonists during the 1 year period before the index date, as well as for current, new, and first time use. In all instances the rate ratios are close to unity and not significant. However, although not significant, the quantity-response analysis suggests a small increase in the risk of acute MI of $11 \%$ (95\% CI -1 to 23 ) for every 10 canisters of inhaled $\beta$ agonists dispensed during the year before the index date.
Table 3 presents the analyses of current, new, and first time use stratified by the presence of cardiovascular disease or risk factors before the index date. Here again, the rate ratios are close to unity and not significant. In particular, the rate ratio for first time use of inhaled $\beta$ agonists among patients with concomitant cardiovascular disease or risk factors was 0.99 (95\% CI 0.56 to 1.73 ). Moreover, the rate ratios were practically unchanged among the patients who did not use $\beta$ blockers.

Table 4 shows that the rate ratios are close to unity and not significant for other forms of $\beta$ agonists (nebulised and oral) irrespective of the quantity or timing of their use.

\section{DISCUSSION}

Beta agonists, including inhaled, nebulised, and oral forms, are not associated with a risk of fatal or non-fatal acute MI in patients with COPD. In addition, first time use of inhaled $\beta$ 
agonists by patients with and without pre-existing concomitant cardiovascular disease was found to be unrelated to acute MI.

Our findings contradict the one potentially troubling result of the case-control study by $\mathrm{Au}$ et $a l^{6}$-namely, that first time use of inhaled $\beta$ agonists in people with existing cardiovascular disease increases the risk of MI. That study, however, had several shortcomings in design that could have biased their finding and explain their divergent results. Firstly, it included a majority of patients who did not have asthma or COPD, the usual indication for inhaled $\beta$ agonists. Indeed, the reference group of never users of $\beta$ agonists probably contained few patients with COPD and thus only a small minority of the 1444 cases and 4094 controls in that study were relevant to the risk estimate. More importantly, however, since COPD is a known risk factor for acute MI, the analysis should have adjusted for this confounder or, as our study was, been restricted to patients with COPD who are users of these drugs. Secondly, the study by $\mathrm{Au}$ and colleagues failed to assess the concurrent possible protective effect of $\beta$ blockers. The antagonist effect of $\beta$ blockers may neutralise the effects of $\beta$ agonists, so the risk of MI associated with $\beta$ agonists may be different in subjects already using $\beta$ blockers than among non-users of $\beta$ blockers. Since statistical "adjustments" do not resolve such effect modification, we instead re-estimated the risk strictly among non-users of $\beta$ blockers and found no increased risk. We also felt it important to account for the use of oral and nebulised forms of $\beta$ agonists. We consider these to be important potential confounders since they have been shown to be associated with acute cardiac death ${ }^{5}$ and are likely to be prescribed more frequently among subjects prescribed the usual metered dose formulations. Moreover, studying these higher dose formulations is instrumental in assessing dose-response effects of $\beta$ agonists in general. Our analysis of these formulations found no increased risk.

We believe that the more plausible explanation for the observed increased risk found by Au et al soon after one time use of $\beta$ agonists is a misdiagnosis, as asthma or COPD, of angina or other respiratory symptoms associated with an imminent MI. That isolated prescription for an inhaled $\beta$ agonist interpreted as "first time use" was probably prescribed for such symptoms to a patient who did not have asthma or COPD. Indeed, chart reviews revealed the presence of symptoms such as chest pressure, atypical chest pain and pressure, or pleuritic chest pain. We feel that, in view of our unequivocal findings, the observation by $\mathrm{Au}$ et al for first time use is probably the result of diagnostic bias and confounding.

We observed a trend towards a small increase in risk of MI of $11 \%$ for each 10 canisters dispensed within the previous year for frequent or high dose use of $\beta$ agonists. The most likely explanation is that subjects with greater utilisation of these medications have more severe COPD with more profound airflow limitation which is itself the explanation for the increase in risk. ${ }^{7}$ Since we did not have access to measures of lung function, it is likely that adjustments made for severity of COPD were insufficient and that residual confounding is the most likely explanation for this small increase in risk of MI with increasing number of metered dose inhalers of $\beta$ agonists dispensed in the previous year.
Our study has both strengths and limitations. Since the cohort was formed from administrative databases, all that is known is that inhaled $\beta$ agonists were dispensed on a given date, but not whether they were actually taken. We can expect, however, that most were taken as COPD is a disease that requires significant assistance with bronchodilation. This is probably more accurate for subjects who were dispensed a large number of canisters during the year before the index date. Even these subjects had no increased risk of acute MI. The outcome of acute MI has been validated in the Saskatchewan databases and found to be accurate. ${ }^{10}$

In conclusion, we found that short acting $\beta$ agonists in any form did not increase the risk of acute MI in a large cohort of patients with COPD. First time use, in particular, also did not increase the risk.

\section{ACKNOWLEDGEMENT}

This study is based on non-identifiable data provided by the Saskatchewan Department of Health. The interpretation and conclusions contained herein do not necessarily represent those of the government of Saskatchewan or the Saskatchewan Department of Health.

\section{Authors' affiliations}

S Suissa, T Assimes, P Ernst, Division of Clinical Epidemiology, Royal Victoria Hospital, McGill University Health Centre, and Departments of Epidemiology and Biostatistics and of Medicine, McGill University, Montreal, Canada

P Ernst, Division of Respiratory Medicine, McGill University Health Centre

This study was funded by grants from the Canadian Institutes for Health Research (CIHR), AstraZeneca, Boehringer-Ingelheim, and GlaxoSmithKline. Dr Suissa is the recipient of a Distinguished Scientist award from CIHR. Dr Assimes received a studentship award from the FRSQ during the study period. The McGill Pharmacoepidemiology Research Unit is funded by an infrastructure grant from the Fonds de la recherche en santé du Québec (FRSQ).

\section{REFERENCES}

1 Burgess CD, Flatt $A$, Siebers $R$, et al. A comparison of the extent and duration of hypokalaemia following three nebulized beta $_{2}$-adrenoceptor agonists. Eur J Clin Pharmacol 1989·36:415-7.

2 Kiely DG, Cargill RI, Grove A, et al. Abnormal myocardial repolarisation in response to hypoxaemia and fenoterol. Thorax 1995;50:1062-6.

3 Maesen FPV, Costongs R, Smeets JJ, et al. The effect of maximal doses of formoterol and salbutamol from a metered dose inhaler on pulse rates, ECG, and serum potassium concentrations. Chest 1991;99:1367-73.

4 Lipworth BJ. Risks versus benefits of inhaled beta 2 -agonists in the management of asthma. Drug Saf 1992;7:54-70.

5 Suissa S, Hemmelgarn B, Blais L, et al. Bronchodilators and acute cardiac death. Am J Respir Crit Care Med 1996;154:1598-602.

6 Au DH, Lemaitre RN, Curtis JR, et al. The risk of myocardial infarction associated with inhaled beta-adrenoceptor agonists. Am J Respir Crit Care Med 2000;161:827-30.

7 Hole DJ, Watt GCM, Davey-Smith G, et al. Impaired lung function and mortality risk in men and women: findings from the Renfrew and Paisley prospective population study. BMV 1996:313:711-5.

8 Downey W, Beck P, McNutt M, et al. Health databases in Saskatchewan. In: Strom BL, ed. Pharmacoepidemiology. 3rd ed. New York: John Wiley \& Sons, 2000: 325-46.

9 Suissa S. Novel approaches to pharmacoepidemiological study design and statistical analysis. In: Strom BL, ed. Pharmacoepidemiology. 3rd ed. New York: John Wiley \& Sons, 2000;785-805.

10 Rawson NS, Malcolm E. Validity of the recording of ischaemic heart disease and chronic obstructive pulmonary disease in the Saskatchewan health care datafiles. Stat Med 1995; 14:2627-43. 